\author{
Araştırma Makalesi \\ https://doi.org/10.53803/turvehab.964109
}

\title{
Epilobium alpestre (Onagraceae) Taksonunun Biyosistematik Özellikleri ve Türkiye'deki Yayılışı
}

\author{
Seda Okur (iD) 1, , Serdar Makbul (iD)2, Kamil Coşkunçelebi iD 3 \\ ${ }^{1}$ Bitkisel ve Hayvansal Üretim Bölümü, Pazar Meslek Yüksekokulu, Recep Tayyip Erdoğan Üniversitesi, TR- \\ 53300, Rize, Türkiye \\ ${ }^{2}$ Biyoloji Bölümü, Fen Edebiyat Fakültesi, Recep Tayyip Erdoğan Üniversitesi, TR-53100, Rize, Türkiye \\ ${ }^{3}$ Biyoloji Bölümü, Fen Fakültesi, Karadeniz Teknik Üniversitesi, TR-61080, Trabzon, Türkiye \\ *Yazışmadan sorumlu yazar: Seda Okur, seda.okur@erdogan.edu.tr
}

\begin{tabular}{lll}
\hline Geliş: 07.07.2021 & Kabul: 03.10.2021 & Çevrimiçi Yayın: 31.12.2021 \\
\hline
\end{tabular}

\begin{abstract}
Özet
Daha çok Kafkasya ve Avrupa'da yayılış gösteren Epilobium alpestre, mevcut kayıtlara göre Türkiye'nin kuzeydoğusundan bilinen tek popülasyonla temsil edilmektedir. Bu çalışma ile taksonun Türkiye'deki dağıılımı, ayrıntılı morfolojik özellikleri ile polen ve tohum mikromorfolojik özellikleri verilerek türün sistematiğine katkı sağlanması amaçlanmıştır. E. alpestre, E. montanum taksonu ile yakın benzerlik göstermekle birlikte vertisilat yaprakları, parçalanmamış sitigması ve büyük tohumları $(1,5-2 \mathrm{~mm})$ ile kolaylıkla ayırt edilmektedir. E. alpestre aynı zamanda çubuklu polen süslemesi ve tanecikli-buruşuk tohum yüzeyi özellikleri ile karakterize edilmektedir. Bu çalışma ile E. alpestre'nin Türkiye'de bilinen doğrulanmış tek popülasyon ile temsil edildiği tespit edilmiş ve ayrıntılı morfolojik ve mikromorfolojik özellikleri belirlenerek genişletilmiş betimi yeniden oluşturulmuştur.
\end{abstract}

Anahtar kelimeler: Epilobium alpestre, mikromorfoloji, polen, Türkiye

\section{Distribution and Bio-systematic Characteristics of the Epilobium alpestre (Onagraceae) Taxa in Turkey}

\begin{abstract}
Epilobium alpestre, one of the widespread Epilobium taxa in the Caucasia and Europe, is represented by one known population from the northeast of Turkey according to the current records. This study aimed to contribute to the systematics with botanical, palynological, and seed micromorphological characteristics, and distribution in Turkey of this species. Although E. alpestre closely resembles the E. montanum taxon, it is easily distinguished by its verticillate leaves, unsegmented stigma, and large seeds $(1.5-2 \mathrm{~mm})$. E. alpestre is also characterized baculate ornamentation of pollen and granulate-rugose ormanentation on seed surface. In this study, it was determined that Epilobium alpestre was represented by the only one confirmed population known in Turkey, and its detailed morphological and micromorphological features were determined and its expanded description was reconstructed.
\end{abstract}

Keywords: Epilobium alpestre, micromorphology, pollen, Turkey

\section{GíRiş}

Onagraceae familyasının geniş yayılışlı cinslerinden biri olan Epilobium L. cinsi dünyada yaklaşık 170 türle temsil edilmektedir (Raven 1976; 1988; Hoch \& Raven 1992; Mabberley 1993; Ford \& Gottlieb 2007; Skvarla vd. 2008). Epilobium sensu lato cinsinin önemli taksonomik problemlere sahip olduğu ve geçmişten günümüze kadar farklı sistematik değerlendirmelere maruz kaldığ 1 Önerilen Alınt:

Okur, S., Makbul, S. \& Coşkunçelebi, K. (2021). Epilobium alpestre (Onagraceae) Taksonunun Biyosistematik Özellikleri ve Türkiye'deki Yayılışı. Türler ve Habitatlar 2(2): 86-97. 
bilinmektedir (Chamberlain \& Raven 1972; Chen vd. 1992; Levin vd. 2003; Wagner vd. 2007; Sennikov 2011). Cins içerisinde görülen morfolojik benzerlikler ve taksonlar arası oluşan hibritler bu sistematik problemlerin kaynağını oluşturmaktadır (Holden 1916; Raven 1980; Nieto Feliner 1997, Kitchener \& McKean 1998). Birçok araştırıcı Chamaenerion Adans. cinsini Epilobium altında bir seksiyon olarak değerlendirirken (Haussknecht 1884; Rechinger 1964; Chamberlain \& Raven 1972; Levin vd. 2003) bazı araştırıcılar da Chamaenerion taksonlarının münferit bir cins olarak ele alınması gerektiğini savunmuşlardır (Raimann 1893; Shteinberg 1949; Sennikov 2011). Ülkemiz Epilobium taksonları ile ilgili en kapsamlı çalışma Flora of Turkey and the East Aegean Islands eserinin yazımı esnasında Chamberlain ve Raven (1972) tarafindan yapılmıştır. Chamberlain ve Raven (1972) eserde cinsin 21 türle temsil edildiğini ve Chamaenerion Adans. taksonlarının Epilobium cinsi altında seksiyon düzeyinde değerlendirilmesi gerektiğini iddia etmişlerdir. Ancak son y1llarda Epilobium taksonları üzerinde gerçekleştirilen ayrıntılı biyosistematik çalışmalar Epilobium ve Chamaenerion taksonlarının ayrı birer cins olarak ele alınması gerektiğini ortaya koymaktadır (Coşkunçelebi vd. 2017; Okur 2019). Bu verilere göre ülkemizde yayılış gösteren Epilobium cinsinin 18 türle (22 takson), Chamaenerion cinsinin ise 4 tür/ takson ile temsil edildiği rapor edilmiştir (Okur 2019).

Jacquin (1762), E. alpestre (Jacq.) Krock. taksonunun, E. montanum L. taksonu altında $E$. montanum var. alpestre Jacq. şeklinde varyete olarak ele alınması gerektiğini iddia etmiştir. Ancak Krocker (1787) E. alpestre ve E. montanum taksonlarının münferit iki tür olarak ele alınması gerektiği görüşündedir. Benzer şekilde E. alpestre taksonu Flora of Turkey and the East Aegean Islands, Flora Kavkaza ve Flora of the USSR eserlerinde de sahip olduğu morfolojik özellikler yönünden müstakil bir tür olarak ele alınmıştır (Shteinberg 1949; Grossheim 1962; Chamberlain \& Raven 1972). Son yapılan taksonomik çalışmalar E. alpestre'nin tür düzeyinde ayrı bir takson olarak ele alınması gerektiğini göstermiştir (Wagner vd. 2007; Okur 2012; 2019; Kundakçı 2017; Kundakç1 vd. 2018; Güven vd. 2021 ).

Epilobium alpestre'nin dünyada Kafkasya ile Orta ve Güney Avrupa'da yüksek dağlarda yayılış gösterdiği bilinmektedir (Bolòs \& Vigo 1984; Nieto Feliner 1997). Flora of Turkey and the East Aegean Islands eserinde (Chamberlain \& Raven 1972) verilen E. alpestre kayd1, Flora Kavkaza eserinde (Grossheim 1962) verilen lokasyona dayandırılmış ve türün Türkiye'de sadece Şavşat (Artvin) dolaylarında tek lokalitede var olduğu rapor edilmiştir (Şekil 1). Ancak Flora of Turkey and the East Aegean Islands kaleme alınırken, Grossheim tarafından belirtilen bu örnek görülmediği gibi sonrasında da söz konusu lokaliteden herhangi bir örnek toplanmamıştır. Ayrıca Grossheim tarafından kaydı verilen örneğin de hangi herbaryumda bulunduğuna dair herhangi bir bilgiye de ulaşılamamıştır.

Flora of Turkey and the East Aegean Islands eserinde bu türün Türkiye'deki varlığının teyit edilmesi gerektiği ve dairesel yaprak dizilişi, parçalanmamış stigması ve büyük tohumları ile diğer Epilobium türlerinden kolaylıkla ayrlabileceği belirtilmektedir (Chamberlain \& Raven 1972). Ülkemizden kaydı verilen ancak daha sonra varlığı teyit edilemeyen ve yeni örnekleri toplanamayan bu tür Türkiye Bitkileri Kırmızı Kitabı'nda DD (Yetersiz Verili ) kategorisinde değerlendirilmiştir (Ekim vd. 2000).

Bu çalışma ile Türkiye'de varlığı kesinleşen E. alpestre türünün detaylı morfolojik özelliklerin belirlenerek, polen ve tohum mikro morfolojik özelliklerinin tespit edilmesi ve türün sistematiğine katkı sağlanması amaçlanmıştır. 


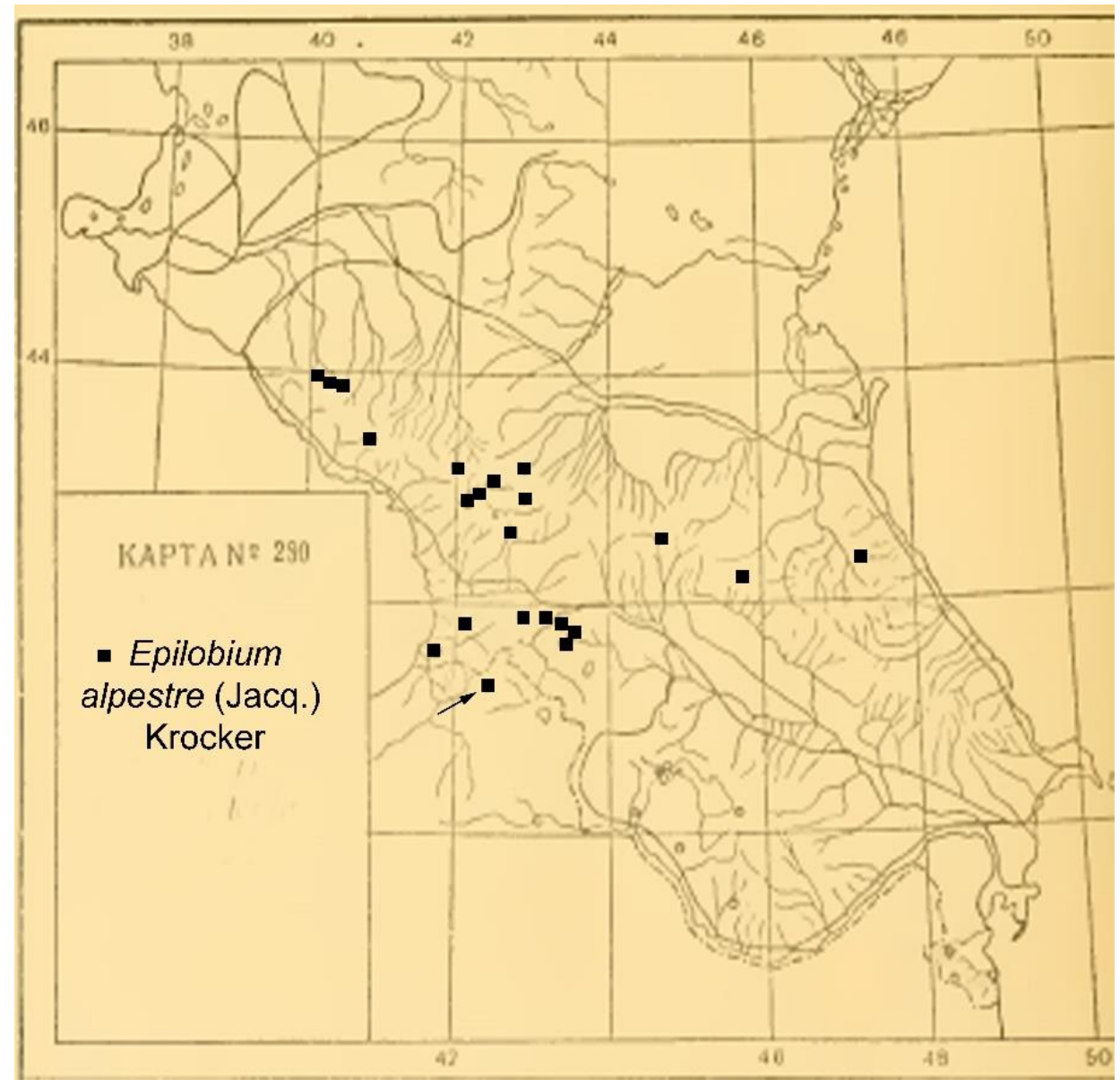

Şekil 1. Flora Kavkaza (Grossheim 1962) eserinde Epilobium alpestre için verilen yayılış haritası (Türkiye'deki yayılışı ok ile gösterilmiştir).

\section{MATERYAL VE METOT}

Çalışmanın materyalini oluşturan bitki örnekleri, TÜBİTAK tarafından desteklenen proje kapsamında toplanmış ve standart herbaryum tekniklerine göre hazırlanarak Recep Tayyip Erdoğan Üniversitesi Fen Edebiyat Fakültesi, Biyoloji Bölümü Herbaryumu (RUB)'nda muhafaza altına alınmıştır. Morfolojik çalışmalarda başta Flora of Turkey and the East Aegean Islands (Chamberlain ve Raven 1972) olmak üzere, Flora of the USSR (Shteinberg 1949), Flora Kavkaza (Grossheim 1962), Flora Europaea (Raven 1968), Flora d'Italia (Pignatti 1982) ve Flora Orientalis eserlerinden (Boissier 1875) yararlanılmıştır. Morfolojik karakterler stereo-binoküler mikroskop altında incelenmiş ve ayrımda önemli olduğu düşünülen çiçek, meyve ve tohum gibi organların detay özellikleri fotoğraflanmıştır. Palinolojik incelemede Erdtman (1952)'nın asetoliz yöntemi ile elde edilen polenler 1 ş1k ve elektron mikroskobunda ayrıntılı olarak incelenmiştir. Tohum mikromorfolojik çalışmalarında Coşkunçelebi vd. (2017) tarafindan kullanılan yöntem takip edilerek hazırlanan tohumlar JEOL JSM-6610 marka taramalı elektron mikroskobunda incelenmiş ve detay özellikleri fotoğraflanmıştır. Polen ve tohum mikromorfolojik incelemelerinde Punt vd. (2007) ve Coşkunçelebi vd. (2016) tarafından kullanılan terminoloji takip edilmiştir. E. alpestre ile E. montanum taksonlarının Türkiye'deki dağılım haritası, saha çalışmalarına ve literatür kayıtlarına dayalı olarak ArcGIS 9.3 programı kullanılarak oluşturulmuştur. Ayrıca taksonun Türkiye'deki dağılışı ve tehdit etmenleri hakkında genel bir değerlendirme yapılmıştır (IUCN 2017). 


\section{SONUÇLAR VE TARTIŞMA}

Epilobium alpestre (Jacq.) Krock., Fl. Siles. 1: 605 (1787) (Şekil 2).

Sintip: Austria, Anon s.n. (BM!).

Sinonim: $\equiv$ Epilobium montanum L. var. alpestre Jacq., Enum. Stirp. Vindob. $64(1762) ;=E$. trigonum Schrank, Baier. Fl. 1: 644 (1789).

Betimleme: Bitki dik, çok yıllık, 20-115 cm boyunda; rizomlu ve stolonlu, kazık kökler yoğun fibrilli; gövde silindirik, 2-4-çizgili, sadece çizgiler boyunca kıvrık tüylü, açık yeşil, dallanmamış, 10-12-çiçekli, tabanda yaprak sapı kalıntıları var. Yapraklar mızraksı, dairesel dizilişli, 2,5-8,0 × 1,0-2,7 cm, koyu yeşil, kenarları seyrek testere dişli, sivri veya sipsivri, tabanı kamamsı, nadiren yuvarlak, damarlar ve yaprak kenarları kıvrık tüylü, sapsız veya nadiren kısa saplı (c. 0,5 mm), yaprak koltuklarında kısa vejetatif sürgünler var. Çiçekdurumu salkım, yoğun salg1 ve yatık tüylü, pedisel 10-15 mm, olgun çiçekler dik ve tomurcuk çiçekler sarkık, aktinomorf; sepal 4 adet, tabanda birleşik, mızraks1, 6,4-6,8 × 1,3-1,5 mm, yeşil, salgı tüylü, sivri; petal 4 adet, serbest, tersyüreksi, 5,5-12,5 $\times$ 2,6-3,2 mm, pembemsi-mor, loblu. Sitamenler 8 adet, iki sıra halinde, dıştakiler 4,4-5,0 mm, içtekiler 2,6-2,8 mm, epipetal; filament tabanda tüylü, antere sirttan bağli; anter 1,0-1,2 mm, boyuna yarıkla açılır. Sitigma tam, baş şeklinde, 1,9-2,2 × 0,4-0,7 mm; stilus 2,8-3,1 mm, tüysüz, sitamenlerden kısa. Kapsül silindirik, 5-8 cm, yeşil, yatık ve seyrek salgı tüylü, meyve sapı 6-10 $\mathrm{mm}$, yoğun yatık ve salg1 tüylü; tohum dar yumurtamsı veya mızraks1, 1,5-2,0 × 0,4-0,5 mm, kahverengi, yüzeyi kabarcıkl1; ucu gagalı ve tabanı sivri; koma 6-10 mm ve krem renkli.

Habitat ve ekoloji: Tür temmuz-ağustos aylarında çiçeklenir ve meyveler ağustos-eylül ayları arasında olgunlaşır. Türkiye'nin kuzeydoğusunda 2000-2500 metre aralığındaki alpin çayırlarda yetişir.

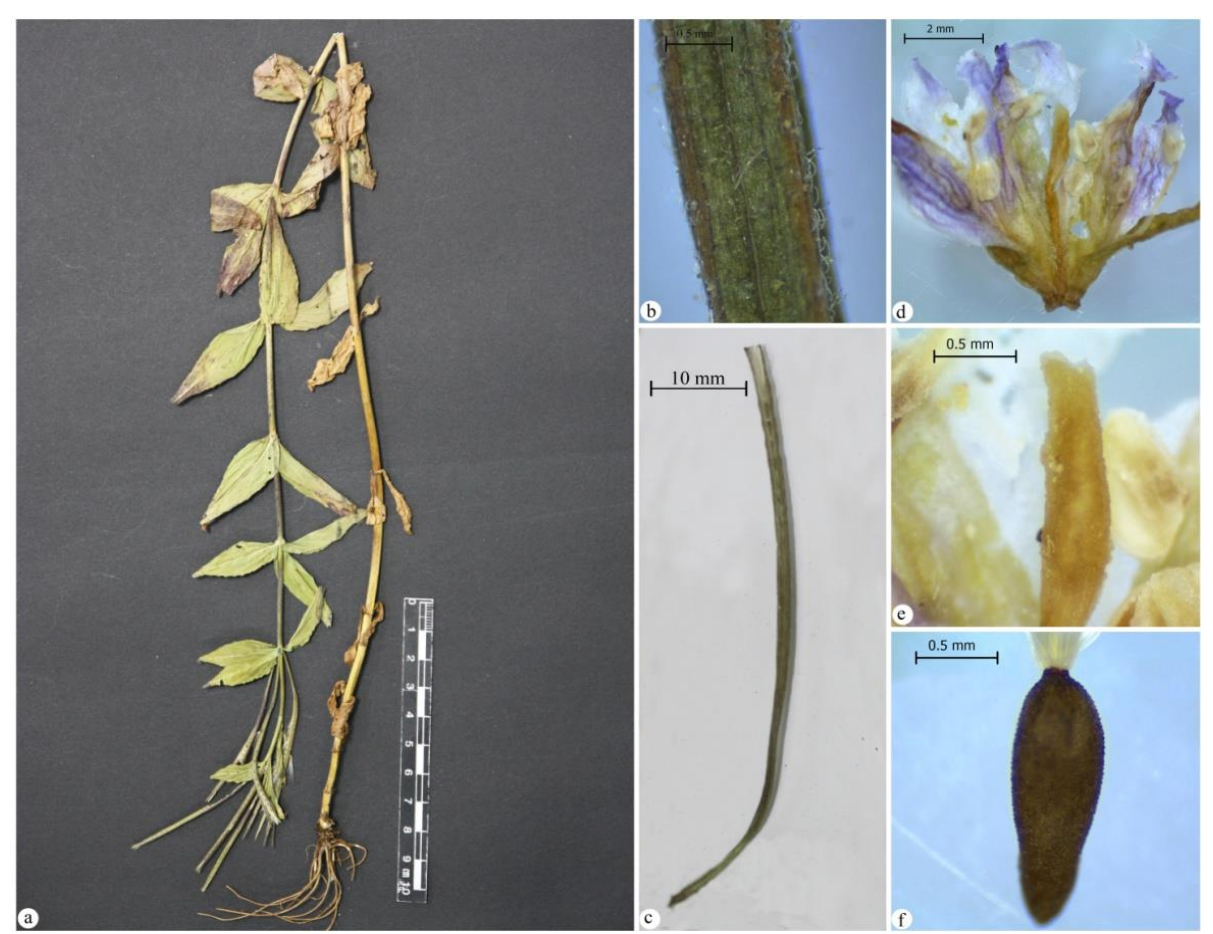

Şekil 2. Epilobium alpestre. a: Habit, b: Meyve yüzeyi, c: Meyve genel görünümü, d: Çiçek, e: Sitigma, f: Tohum. 
Polen morfolojisi: Polenler tetrat, trizonoporat, subisopolar, bilateral simetrik, polar görünüşte üçgenimsi ve proksimal yüzeyde yapışkan iplikler var. Polen şekli suboblat, Polar eksen uzunluğu (P) 44,64 $\pm 2,37 \mu \mathrm{m}$, Ekvatoral eksen uzunluğu (E) 61,54 $\pm 3,13 \mu \mathrm{m}, \mathrm{P} / \mathrm{E} 0,73 \pm 0,04$. Por kanalı uzunluğu (Plg) 10,16 $\pm 0,65 \mu \mathrm{m}$, Por kanalı taban genişliği (Plt) 9,97 $\pm 0,54 \mu \mathrm{m}, \mathrm{Plg} / \mathrm{Plt}$ 0,96 $\pm 0,10$, por genişliği 5,52 $\pm 0,76 \mu \mathrm{m}$, annulus boyu 16,21 $\pm 0,36 \mu \mathrm{m}$. Polar görünüş (amb) çapı 63,43 $\pm 1,93$ $\mu \mathrm{m}$, mezoporium $33 \pm 1,77 \mu \mathrm{m}$, apoporium 33,39 $\pm 2,49 \mu \mathrm{m}$. Ekzin 3,31 $\pm 0,48 \mu \mathrm{m}$, sekzin 1,99 \pm $0,35 \mu \mathrm{m}$, nekzin $1,31 \pm 0,18 \mu \mathrm{m}$ ve ornamentasyon çubuklu (Şekil 3).

Tohum mikro-morfolojisi: Epidermal hücreler 5-6-kenarlı; antiklinal çeperler belirgin, düz ve konveks; periklinal çeperler konkav, tanecikli-buruşuk, kabarcık 14,07-15,55 $\mu \mathrm{m}$, yarı küremsi, yüzeyi düzensiz çizgili, tanecikli ve buruşuk (Şekil 4).

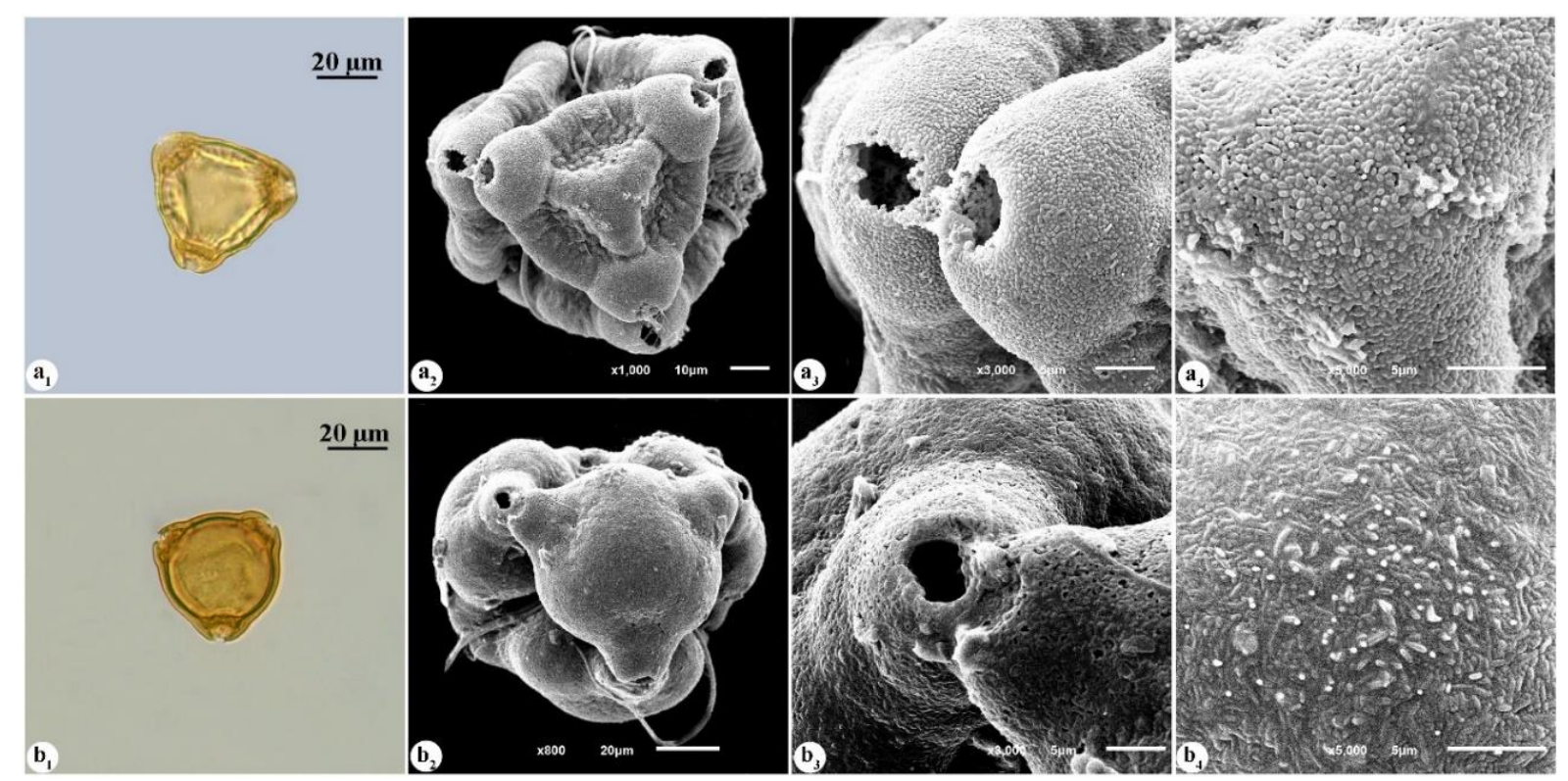

Şekil 3. E. alpestre (a) ve E. montanum (b) polen fotoğrafları: 1. Polar görünüş (IM), 2. Tetrahedral tetrad görünüş (SEM), 3. Por (SEM), 4. Ornemantasyon (SEM).

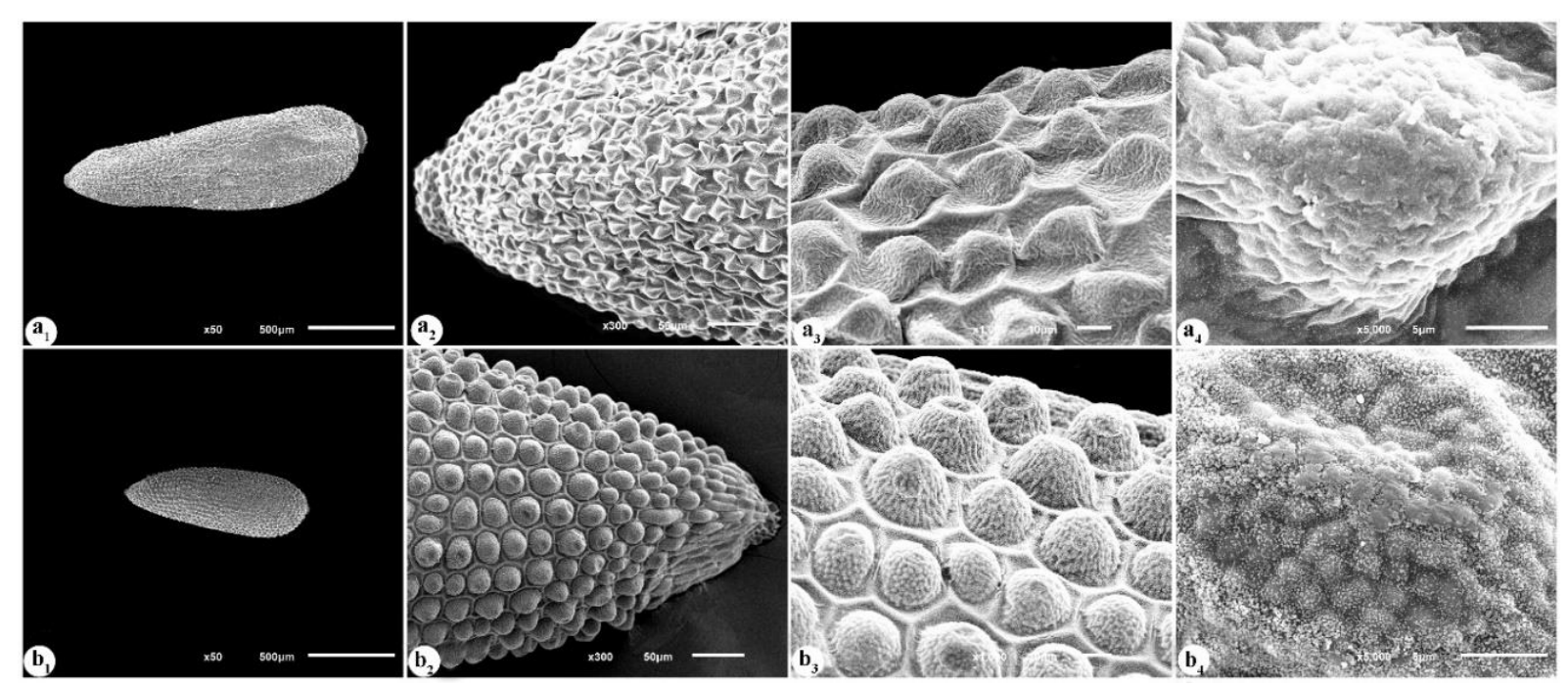

Şekil 4. E. alpestre (a) ve E. montanum (b) tohum yüzeyi SEM mikrofotoğrafları: 1. 50x, 2. 300x, 3. 1000x, 4. 5000x (Coşkunçelebi vd. 2017). 


\section{Taksonomik notlar}

Epilobium alpestre ülkemizde tek lokaliteden kayıt verilen, uzun zamandır izine rastlanamayan ve ülkemizdeki varlığının kesinleştirilmesi gereken taksonlardan birisidir. Ayrıca E. montanum ile yakın morfolojik benzerlikler göstermesi nedeni ile taksonomik problemlere sahip olduğundan birçok araştırıcı tarafından farklı sınıflandırmalara tabi tutulmuştur (Jacquin 1762; Krocker 1787; Grossheim 1962; Chamberlain \& Raven 1972; Wagner vd. 2007). Epilobium alpestre ile E. montanum türlerinin morfolojik ve mikro-morfolojik özellikler bakımından taksonomik karşılaştırması Tablo 1'de verilmiştir.

Tablo 1. Epilobium alpestre ve E. montanum'un morfolojik karşılaştırılması.

\begin{tabular}{|l|l|l|}
\hline Karakterler & E. alpestre & E. montanum \\
\hline Gövde tüyü & sadece çizgiler boyunca kıvrık tüylü & yoğun kıvrık tüylü \\
\hline Yaprak dizilişi & dairesel & karş1lılı \\
\hline Kaliks tüyü & salgı tüylü & salg1 ve yatık tüylü \\
\hline Sitigma & tam & $4-$ loblu \\
\hline Tohum boyu & $1,50-2,00 \mathrm{~mm}$ & $1,00-1,19 \mathrm{~mm}$ \\
\hline Tohum ucu & gagalı & gagasız \\
\hline Tohum yüzeyi & tanecikli-buruşuk & tanecikli-kaba pürüzlü \\
\hline Polen yüzeyi & çubuklu & düzensiz çizgili \\
\hline
\end{tabular}

Jacquin (1762), Epilobium alpestre taksonunun morfolojik özelliklere göre E. montanum taksonunun varyetesi olarak ele alınması gerektiğini rapor etmiştir. Ancak elde edilen morfolojik verilere göre $E$. alpestre, stigmasının tam olması ve dairesel yaprak dizilişi ile E. montanum'dan kolaylıkla ayrılabilmektedir (Şekil 2). Haussknecht (1884) ve Shteinberg (1949) Epilobium cinsinin Lysimachion Tausch seksiyonunu stigma özellikleri yönünden iki alt gruba ayırmışlardır. Stigmas1 tam olanları Synstigma grubuna dâhil edilirken parçalı stigması olanlar ise Schizostigma grubuna aktarılmıştır. Buna göre E. montanum taksonu Schziostigma grubunda yer alırken E. alpestre Synstigma içerisinde listelenmiştir (Haussknecht 1884; Shteinberg 1949). Epilobium cinsi üyeleri genellikle alternat ya da opposit yaprak dizilişi ile karakterize edilmektedir (Chamberlain \& Raven 1972; Okur 2019). Ancak dairesel yaprak dizilişine sahip olan E. alpestre, diğer Epilobium taksonlarından kolaylıkla ayrılmaktadır. E. alpestre taksonu parçalı stigması ve dairesel yaprak dizilişi ile belirgin şekilde E. montanum'dan ayrılmakta ve elde edilen detay morfolojik özelikler de bu iki taksonun tür kategorisinde yer alması gerektiğini desteklemektedir (Tablo 1).

Tohum büyüklüğü ve çiçek durumundaki çiçeklerin pozisyonları da Epilobium taksonları arasında önemli bir ayırım sağlamaktadır (Chamberlain \& Raven 1972; Okur 2019). E. alpestre büyük tohumları $(1,50-2,00 \mathrm{~mm})$ ve tomurcuk çiçeklerinin sarkık olması ile yakın benzerlik gösterdiği daha küçük tohumlu $(1,00-1,19 \mathrm{~mm})$ ve dik çiçek tomurcuklarına sahip E. montanum taksonundan kolaylıkla ayrılmaktadır (Tablo 1).

Tüylenme ve tohum yüzeyi süslemesi gibi özellikler değişkenlik göstermektedir (Coşkunçelebi vd. 2017; Okur 2019). Makbul vd. (2015) ve Krajsek vd. (2006) gövdedeki tüy dağ1lımının Epilobium cinsinde farklılık gösterdiğini rapor etmişlerdir. E. alpestre gövdesi sadece çizgiler boyunca kıvrık tüylü iken, E. montanum'un tüm gövdesi yoğun kıvrık tüylüdür. Benzer şekilde $E$. alpestre yaprakları sadece damar ve kenar boyunca kıvrık tüylü iken, E. montanum yapraklarının damar ve kenarları 
daha yoğun olmak üzere tüm yüzeyi kıvrık tüylüdür. Yine E. alpestre sepalleri salgı tüylü ve gagalı tohumlu olması ile sepalleri salgı ve yatık tüylü, tohumları gagasız olan E. montanum türünden farkl11ık göstermektedir (Tablo 1).

Epilobium cinsinde palinolojik ve mikromorfolojik özellikler taksonların ayrımında önemli katkılar sağlamaktadır (Coşkunçelebi vd. 2017; Rahimi vd. 2018). E. alpestre taksonunun polenleri çubuklu ornamentasyona sahipken, E. montanum polenleri düzensiz çizgilidir. Benzer şekilde $E$. alpestre'nin tohum yüzeyi tanecikli ve buruşuk iken, E. montanum'un tohum yüzeyinin yoğun tanecikli ve kaba pürüzlü olduğu tespit edilmiştir. Polen ve tohuma ait mikromorfolojik özellikler, bu taksonların ayrımında önemli katkılar sağlamakta ve iki taksonun münferit türler olarak ele alınması gerektiğini destekler niteliktedir (Tablo 1).

Epilobium üyeleri yaşam alanı olarak genellikle sucul ya da nemli habitatları tercih ederler (Chamberlain ve Raven; 1972). Türkiye'de genellikle nemli bir iklime sahip olan Karadeniz bölgesinde yoğunlaşan taksonlar diğer bölgelerde daha çok su kaynaklarına yakın alanlarda yayılış göstermektedir (Okur 2019). Ülkemizde çok sayıda popülasyon ile temsil edilen E. montanum taksonu Karadeniz bölgesinde yoğun olmak üzere tüm Türkiye'de yayılış gösterirken E. alpestre'nin sadece Doğu Karadeniz bölgesinde ve dar bir alanda yayılış gösterdiği tespit edilmiştir. E. montanum 300-2500 m arasındaki yükseltilerde ve genellikle orman altı habitatlarda yayılış gösterirken, $E$. alpestre 2000 m üzerindeki alpinik çayır habitatlarını tercih etmektedir.

\section{Yayılış ve koruma durumu}

Flora of Turkey and the East Aegean Islands eserinde Epilobium alpestre taksonu Grossheim tarafından verilen bir kayda dayanılarak "A9 Çoruh: Şavşat” şeklinde tek lokaliteden verilmiştir (Chamberlain \& Raven 1972). Şavşat civarında gerçekleştirilen arazi çalışmalarında bu taksona ait örneklere rastlanmamıştır. Yapılan detaylı saha çalışmalarında taksona ait örnekler "A8 Rize: Yukarı Kavrun Yaylası" adresinden toplanmıştır (Şekil 5).

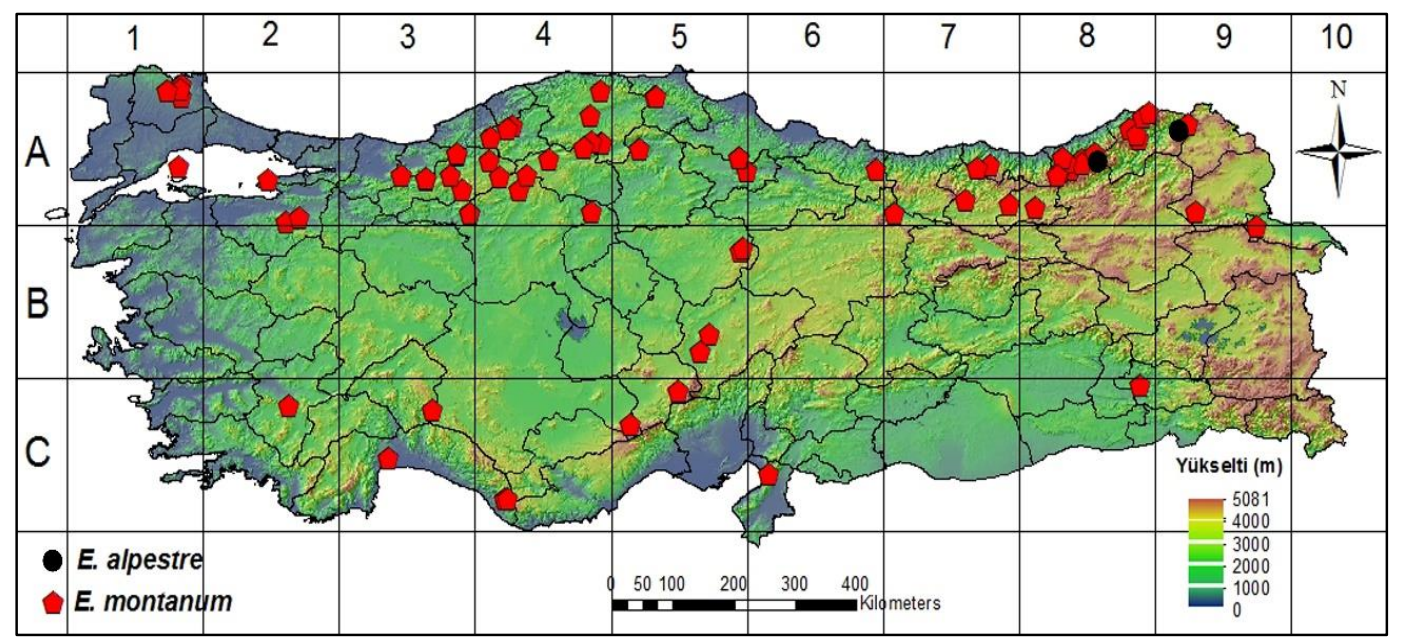

Şekil 5. Epilobium alpestre ve E. montanum taksonlarının Türkiye'deki dağılışı.

Türün dağılış alanının (EOO) $8 \mathrm{~km}^{2}$, yaşam alanının (AOO) ise $1 \mathrm{~km}^{2}$ olduğu tespit edilmiştir. Bu türün sağlıklı birey sayısı oldukça az olup yaşam alanı yaylacılık faaliyetlerinin baskısı altındadır. Öte yandan E. alpestre Türkiye'de oldukça dar bir dağılış alanına sahipken, genel olarak Kafkasya, Orta ve Güney Avrupa'da nispeten daha geniş bir dağılışa sahiptir. Taksonun tehdit kategorisinin belirlenebilmesi için dağılış gösterdiği tüm alanlardaki popülasyon durumu ve tehditler birlikte 
değerlendirilmelidir (IUCN 2017). Bu yüzden, burada E. alpestre'nin sadece Türkiye'deki dağılış ve yaşam alanı genişliği ile tehditler hakkında bilgi verilmesiyle yetinilmiştir.

Bu çalışmada; Epilobium alpestre türünün morfolojik özellikleri detaylandırılmış, polen ve tohum mikromorfolojik özellikleri belirlenmiş, Türkiye'deki yayılışı ve habitat tercihi hakkındaki bilgiler güncellenmiş, yapılan gözlemlerle üzerindeki tehditler tespit edilmiş, taksonomik olarak yakın olan E. montanum ile karşılaştırılmış ve nihayet tüm bu bulgular 1şığında taksonun sistematiğine katkı sağlanmıştır.

\section{İncelenen örnekler}

Epilobium alpestre: TÜRKIYE. A8 Rize: Çamlıhemşin, Yukarı Kavrun Yaylası, alpin çayırlar, 2213 m, 19.07.2012, S.Okur 90 \& S.Makbul (Recep Tayyip Erdoğan Üniversitesi Fen Edebiyat Fakültesi, Biyoloji Bölümü Herbaryumu - RUB!).

Epilobium montanum: TÜRKIYY. A1 Kırklareli: Mahya Dağ1 yolu, yol kenarı, 784 m, 16.07.2013, S.Okur 184 \& S.Makbul (RUB!); Sergen-Demirköy yolu, orman alt1, 18.06.1974, A.Baytop (ISTE 29942!); Mahya Dağı, Bayındırlık Tepesinin kuzeydoğu yamaçları, 28.06.1974, N.Özhatay \& E.Özhatay (ISTE 30064!); Kırklareli-Demirköy arası, Balaban Köprüsü, 29.08.1974, N.Özhatay \& E.Özhatay (ISTE 30661!); Demirköy yolu, Haydut Çeşmesi yakımı, 800 m, 26.06.1968, A.Baytop (ISTE 13872!); A2 Bursa: Uludă̆ Mili Park1, yol kenarı, $1751 \mathrm{~m}, 06.08 .2014$, S.Okur 349 \& S.Makbul (RUB!); Uludağ yolu, su kenar1, 1850 m, 25.08.1971, A.Baytop \& T.Baytop (ISTE 20981!); Bursa, Kitirli Dağı, 1874, Pichlerl s.n. (Hb?); A3 Bolu: Mengen, Elemen Yaylası yolu, yol kenar1, 1238 m, 04.09.2015, S.Okur 560 \& S.Makbul (RUB!); Bolu işletmesi, Kökez bölgesi, 1565 m, 12.07.1977, H.Aksoy 207 (ISTO 25607!); Yedigöl yolu, yol ayrımından $28 \mathrm{~km}$ ileride, 12.10.1970, A.Baytop (ISTE 18650!); Yedigöller Milli Park1, bataklık, 800 m, 14.07.1984, E.Leblebici 4978(EGE 33657!); Bolu-Aladağ aras1, Abies orman1, 1600 m, 14.08.1983, M.Vural 2691 (ISTE 72589!); Gerede, Aktaş ormanı, Kurupınar Yayla, Juniperus birliği, 1750 m, 09.07.1976, O.Ketenoğlu 337 (ANK!); Abant Gölü, 27.07.1941, B.Post s.n. (Hb?); Düzce: Balıklı Yaylası, Kayın-Göknar ormanı, 1300-1800 m, 16.06.2003, N.Aksoy 4007 (ISTO 30655!); Ankara: Beypazar1, Tataralan Deresi, 20.07.1972, Y.Akman 9875 (ISTO 25420!); Beypazar1, Tataralan deresi, 20.07.1975, Y.Akman 8375 (ANK!); A4 Kastamonu: Araç'a 20 km, Bayramören-Araç arası, Ilgaz Milli Parkı, yol kenarı, 1666 m, 04.08.2014, S.Okur 329 \& S.Makbul (RUB!); Ilgaz Dağ1, Ilgaz Milli Park1, telesiyej yolu, yol kenar1, 1757 m, 03.08.2018, S.Okur 619 \& S.Makbul (RUB!); Azdavay'dan Daday'a 16. km, yol kenarı, 1369 m, 05.08.2018, S.Okur 636b \& S.Makbul (RUB!); Ilgaz Dağı, Çilesiz, Abies-Pinus sylvestris ormanı, 1600 m, 18.07.1982, Y.Akman 12444 (ANK!); Ilgaz Dağları, Tüfekçi köyü, 1500 m, 23.07.1981, E.Yurdakulol 11724 (EGE 27122!); Zonguldak: Karabük, Büyükdüz bölgesiBüyükdüz serisi, 1430 m, 21.07.1968, M.Aksoy (ISTO 15826!); Karabük: Yenice işletmesi, Çitdere bölgesi, 1370 m, 23.08.1982, G.Özalp (ISTO 26388!); ayn1 yer, 1100 m, 23.08.1982, G. Özalp (ISTO 26389!); Çimşir Dere, Yenice yukarıları, 780 m, Davis 37824 (Hb?); Ankara: Kızılcahamam, tarla araları, 1000 m, 27.07.1989, M.Nessbitt \& J.Samuel 2540 (GAZI!); Çankırı: Işık Dağı, Juniperus nana içinde, 1700 m, 27.06.1975, Y.Akman 6463 (ANK!); Atkaracalar, Dumanlı Dağı, Atkaracalar Yaylası, Çalılıçukur Deresi, dere kenarı, 1350-1500 m, 05.07.1991, A.Duran 1236 (GAZI!); Ilgaz, Ilgaz Dağları, 2000 m, 20.07.1985, Ş. Yıldırımlı 8690 (HUB 14936!); Kırıkkale: Sulakyurt çevresi, çeşme önü, 950 m, 19.07.1990, A.Dönmez 2799 (HUB 14930!); A5 Sinop: Boyabat-Ayancık, Küre Dağları, orman içi, yol kenarı, 1362 m, 04.08.2014, S.Okur 315 \& S.Makbul (RUB!); BoyabatAyancık yolu, Küre Dağları, Çangal Dağı, orman yolu, sulak yerler, 1464 m, 04.08.2014, S.Okur 318 
\& S.Makbul (RUB!); Amasya: Akdağ, Kocacık Tepe, Har Yaylas1, 1300 m, 07.10.1978, Alpınar (ISTE 41367!); Kastamonu: Devrekani, Yaralı̈öz Dağ1, kalker, 1450 m, 13.06.1991, E.Yurdakulol 3213 (ANK!); Ilgaz Dağı'nın kuzey yamaçları, 2000 m, Davis 38324 (Hb?); Abana-Kastamonu, Arpalıkbaşı mevkisi, yol şevleri, kayalık yerler, 710 m, 19.08.2000, E.Kanoğlu (KATO 14521!); Cide, Kızılcasu bölgsi, 1000 m, 11.07.1980, M.İnan \& B.Calap (KATO 5237!); Çorum: Karg1, Kös Dağı, P. sylvestris ormanı, dere kenarları, 1650 m, 15.09.1978, M.Kılınç 4069 (ANK!); A6 Samsun: Ladik, Akdağ, orman altı, 1388 m, 21.07.2014, S.Okur 279 \& S.Makbul (RUB!); Akdağ, yol kenar1, ağaç altı, 1260 m, 21.07.2014, S.Okur 282 \& S.Makbul (RUB!); Akdağ, yol kenarı, ağaç alt1, 1260 m, 21.07.2014, S.Okur 283 \& S.Makbul (RUB!); Ordu: Çambaşıi'nın aşağıları, 1400 m, Tobey 1299; A7 Gümüşhane: Torul-Şiran yolu, Tersun Dağ1, yol kenarı, 1566 m, 11.07.2015, S.Okur 451 \& S.Makbul (RUB!); Trabzon: Tonya, Boğuşlu Yaylası, yol kenarı, yamaç, 1760 m, 10.09.2014, S.Okur 425 \& S.Makbul (RUB!); Giresun: Bulancak, Bicik, 1600 m, 16.08.1978, M.Küçük \& I.Bektaş (KATO 1076!); Bulancak, Bicik, orman içi açıklık, dere kenarlarında, 1500-1600 m, 20.06.1995, M.Arslan (KATO 7795!); Espiye, Karadoğa bölgesi, merekler mevkisi, $1530 \mathrm{~m}$, 08.08.1975, A.Küçükosmanoğlu \& H.Kuruçelik (KATO 1966!); Dereli, Kümbet-Güdül deresi, Güdül ormanları, 1050 m, 03.08.1973, N.Merev (KATO 1703!); Gümüşhane: Kürtün, Örümcek Ormanı, Elceyiz Yaylası civarı, orman içi, 08.08.1990, M.Küçük (KATO 9123!); Trabzon: Maçka, Sümela, sulak yerler, 700 m, 15.07.1989, Ö.Eyüboğlu 1038 (GAZI!); Maçka, Çamlıdüz Yaylası, orman içi, 1786 m, 20.07.2008, A.Uzun (KATO 17975!); Maçka, Altındere Vadisi, Haliya Yaylası, alpin vejetasyon, dere kenar1, 1935 m, 13.07.2001, S.Palabaş (KATO 15446!); Maçka, Altındere Vadisi, Sümela yöresi, orman içi açıklıklar, dere kenarı açıklıklar, nemli alanlar, 1460 m, 24.07.2001, A.Uzun (KATO 14925!); Maçka, Gürgenağaç köyü, Kirazlık yöresi, 1760 m, 18.08.1973, R.Anşin (KATO 1026!); Tonya, Fol Deresi Vadisi, Hoşarlı yöresi, 780 m, 17.06.1979, O.Beşel \& A.Demirci (KATO 4215!); Şalpazarı, Kızılkaya, 1605 m, 25.07.2007, S.Palabaş (KATO 16298!); Şalpazarı, GeyikliÇanakçıbaşı, çalılık alan, 1230 m, 21.06.2006, S.Palabaş (KATO 16466!); Şalpazarı, Cinlik mahallesi, Kayın ormanı altı, 1547 m, 26.07.2007, S.Palabaş (KATO 16871!); A8 Rize: İkizdere, Anzer yolu, yol kenarı, taşlık alan, 1370 m, 28.07.2011, S.Okur 13 \& S.Makbul (RUB!); Çat, Ortaköy, yol kenarı, 1744 m, S.Okur 201 \& S.Makbul (RUB!); Çamlıhemşin, Zilkale-Çat arası, yol kenarı, 1164 m, 25.07.2013, S.Okur 197 \& S.Makbul (RUB!); Yukarı Kavrun, yol kenar1, 1516 m, 19.07.2012, S.Okur 86 \& S.Makbul (RUB!); İspir, Dereköy’ün 3,5 km güneyi, Çamlık köyü, 120 m, 21.08.1976, P.Buttler 21703 (ANK!); İkizdere, Güneyce, orman içi açıklık, 280 m, 29.08.1993, S.Terzioğlu (KATO 10266!); Trabzon: Maçka, Sümela Manastırı, su kenarı, 1889 m, 22.06.2012, S.Okur 61 \& S.Makbul (RUB!); Uzungöl, Arpaözü köyü, orman içi açıklıklarda, 1600 m, 30.08.1996, S.Terzioğlu (KATO 12279!); Uzungöl, göl kenarı, nemli alanlar, 1050 m, 14.08.1996, S.Terzioğlu (KATO 12278!); Çaykara, Uzungöl, belediye merkezi etrafı, 1119 m, 23.07.1987, G. Cevahir (KATO 7755!); Artvin: Artvin, çayırlık mevkisi, açıklıklar, 1700 m, 19.06.1978, R.Anşin (KATO 2261!); Yanıklı köyü (Natanglav) düzlüğü, 1680 m, 22.07.1978, R.Anşin (KATO 2554!; ISTO 32659!); Göktaş-Borçka yolu, Alaca Dağ, kuzey yamaç, 1040 m, 26.06.1877, A.Düzenli 1057 (HUB 14932!); Şavşat, Karagöl, orman açıklıkları, 1700 m, 02.07.2004, H.Altınözlü 4021 (HUB!); Hatila Vadisi, orman içi açık alanlar, 1850 m, 13.07.1995, Ö.Eminağaoğlu (KATO 10705!); A9 Artvin: Borçka, Camili yolu, Karagöl, Alnus sp. açıklıkları, 1150 m, 16.06.2014, S.Okur 227 \& S.Makbul (RUB!); Borçka, Camili-Uğurköy arası, yol kenarı, 543 m, 16.06.2014, S.Okur 229a \& S.Makbul (RUB!); Şavşat, Karagöl-Sahara Milli Parkı, Kocabey Kışlası, akarsu kenarı, 1750 m, 12.08.1999, Ö.Eminăgaoğlu (KATO 13865!); B1 Balıkesir: İvrindi-Korucu, Çetindere yöresi, $850 \mathrm{~m}$, 
02.08.1980, E.Yücel (KATO 5477!); B3 Bolu: Abant, Kazandelen yokuşu, 1300 m, 13.07.1978, Y.Akman 9728 (ANK!); B5 Yozgat: Akdağmadeni, Gül Deresi kenarları, 1400 m, 07.07.1979, T.Ekim 4911 (ANK!); Akdağmadeni, Sırıklı, dere kenarı, 1400 m, 22.08.1979, T.Ekim 4442 (ANK!); Kayseri: Sultansazlığı, Develi ilçesi, Soysallı köyü, Çardakbaşı mevkisi, bataklık, $1071 \mathrm{~m}$, 11.06.1994, M.Öztekin 1516 (HUB 37950!); Erciyes Dağ1, 2300 m, 1902, Zederbauer s.n. (Hb?); B6 Sivas: Suşehri-Zara arası, Şarköy yol ayrımı, 11.07.2015, S.Okur 454 \& S.Makbul (RUB!); B9 Iğdır: Tuzluca, Akdeğirmen köyü, 1735 m, 21.07.2008, E.Altundă̆ 961 (ISTE 85772!); C2 Denizli: Honaz Dağı, Atalanı Yaylası, sulak yerler, 1550 m, 25.07.1973, E.Tuzlacı (ISTE 26598!); C3 Antalya: Aksu, Düden çağlayanı, 06.09.1988, Ş.Ylldırımlı 11586 (HUB 14931!); Konya: Beyşehir, Kurucuova, Dedegöl Dağ1, serpentin, 1700-1800 m, 28.08.1998, H.Altınözlü 2892 (HUB!); C4 Antalya: Gazipaşa, Sugözü köyü, Ekinçalı Yaylası, 12.07.1982, H.Sümbül 1316 (HUB 14934!); Gazipaşa, Çayıryakası Yaylası, 1700 m, 14.07.1983, H.Sümbül 2353 (HUB 14935!); C5 Konya: Ereğli, Aydos Dağı, çakıllar, bozkır, 1400 m, 29.08.1977, S.Erik 2480 (HUB 14933!); Niğde: Bereketli Maden, 1550 m, Ellenberg 45 (Hb?); C6 Hatay: Gavur Dağı, 1200 m, Haradjian 316 (Hb?); C8 Siirt: Kurtalan, Başur Çayı, bataklık, 480 m, 16.05.2009, S.Aslan 3597 (GAZI!).

\section{TEŞEKKÜR}

Bu çalışma KBAG-113Z782 numaralı TÜBİTAK projesi tarafından desteklenmiştir.

\section{YAZAR KATKI BEYANI}

Bu makalede; çalışma fikri ve tasarımı, veri toplama, sonuçların analizi ve yorumlanması, makale taslağının yazımı aşamaları Seda Okur, Serdar Makbul ve Kamil Coşkunçelebi tarafından yapılmıştır. Yazarlar sonuçları gözden geçirmiş, baskı öncesi makalenin son halini kontrol etmiş ve onaylamıştır.

\section{KAYNAKLAR}

Boissier, E.P. (1875). Flora Orientalis. Vol. 3. H. Georg Bibliopolam, Genéva \& Basel, pp 745-751. Bolòs, O. \& Vigo, J. (1984). Flora dels Països Catalans. Vol. 1. Barcino. Barcelona.

Chamberlain, D.F. \& Raven, P.H. (1972). [Epilobium L.] In: Davis, P.H. [Ed.] Flora of Turkey and the East Aegean Islands. Vol. 4. Edinburgh University Press, Edinburgh, pp. 183-196.

Chen, C., Hoch, P.C. \& Raven, P.H. (1992). Systematics of Epilobium (Onagraceae) in China. Systematic Botany Monographs 34: 1-209.

Coşkunçelebi, K., Makbul, S. \& Okur, S. (2016). Studies on the achene morphology of Turkish species of Scorzonera L. (Asteraceae) using light and scanning electron microscopy. Phytotaxa 247(1): 1-26. DOI: https://doi.org/10.11646/phytotaxa.247.1.1.

Coşkunçelebi, K., Makbul, S. \& Okur, S. (2017). Seed morphology of Epilobium and Chamaenerion (Onagraceae) in Turkey. Phytotaxa 331(2): 169-184. DOI: https://doi.org/ 10.11646/phytotaxa.331.2.2.

Ekim, T., Koyuncu, M., Vural, M., Duman, H., Aytaç, Z. \& Adiguzel, N. (2000). Red Data Book of Turkish Plants. Türkiye Tabiatını Koruma Derneği \& Van Yüzüncü Y1l Üniversitesi Yayınları, Ankara.

Erdtman, G. (1952). Pollen Morphology and Plant Taxonomy. Almqvist \& Wiksell, Stockholm, pp. 133-134.

Ford, V.S. \& Gottlieb, L.D. (2007). Tribal relationships within Onagraceae inferred from PgiC sequences. Systematic Botany 32(2): 348-356. 
Grossheim, A.A. (1962). Flora Kavkaza. Vol. 6. Akademiia nauk SSSR, Leningrad. (Rusça, Kiril alfabesi).

Güven, S., Makbul, S., Mertayak, F. \& Coşkunçelebi, K. (2021). Anatomical properties of Epilobium and Chamaenerion from a taxonomical perspective in Turkey. Protoplasma 258(3): 827-847. DOI: $10.1007 / \mathrm{s} 00709-020-01602-0$.

Haussknecht, C. (1884). Monographie der Gattung Epilobium. Fischer, Jena.

Hoch, P.C. \& Raven, P.H. (1992). Proposal to reject the name Epilobium brachycarpum Presl (Onagraceae). Taxon 30(3): 666. DOI: https://doi.org/10.2307/1219961.

Holden, R. (1916). Hybrids of the Genus Epilobium. The American Naturalist 50: 243-247.

IUCN (2017). Guidelines for using the IUCN Red List categories and criteria. Version 13. IUCN Species Survival Commission, Gland.

Jacquin, N.J. (1762). Enumeratio Stirpium Pleraumque, quae sponte crescunt in agro Vindobonensi. Joannis Paulis Kraus, Vindobonae.

Kitchener, G.D. \& McKean, D.R. (1998). Hybrids of Epilobium brunnescens (Cockayne) Raven \& Engelhorn (Onagraceae) and their occurrence in the British Isles. Watsonia 22(1): 49-60.

Krajsek, S.S., Dermastia, M. \& Jogan, N. (2006). Determination key for Central European Epilobium species based on trichome morphology. Botanica Helvetica 116(2): 169-178. DOI: 10.1007/s00035-006-0770-y.

Krocker, A.J. (1787). Flora Silesiaca. Sumptibus G. T. Kornii, Vratislaviae.

Kundakçı, S. (2017). Türkiye Epilobium L. ve Chamerion (Rafinesque) Rafinesque ex Holub (Onagraceae) Taksonlarının nrDna ITS Dizilerine Dayalı Akrabalık İlişkileri (Yüksek Lisans Tezi). Recep Tayyip Erdoğan Üniversitesi, Fen Bilimleri Enstitüsü, Rize.

Kundakçı, S., Makbul, S., Coşkunçelebi, K. \& Gültepe, M. (2018). Comparision of Turkish Epilobium (Onagraceae) s.l. taxa based on matK gene. 1. International Congress on Plant Biology, Konya, Turkey, pp. 182.

Levin, R.A., Wagner, W.L., Hoch, P.C., Nepokroeff, M., Pires, J.C., Zimmer, E.A. \& Sytsma, K.J. (2003). Family-level relationships of Onagraceae based on chloroplast rbcL and ndhF data. Am J Bot 90(1): 107-115. DOI: 10.3732/ajb.90.1.107.

Mabberley, D.J. (1993). The plant book: A portable dictionary of the higher plants. Cambridge University Press, Cambridge.

Makbul, S., Coşkunçelebi, K. \& Okur, S. (2015). Taxonomical Contributions to Turkish Epilobium L. (Onagraceae) taxa based on trichome features. 6. Balkan Botanical Congress, Rijeka, Hirvatistan, pp. 88.

Nieto Feliner, G. (1997). [Epilobium L.] In: Castroviejo, S., Aedo, C., Benedí, C., Laínz, M., Muñoz Garmendia, F., Nieto Feliner, G. \& Paiva J. (Eds.). Flora Iberica. Vol. 8. Real Jardín BotánicoCSIC, Madrid, pp. 101-131.

Okur, S. (2012). [Epilobium L.] In: Güner, A., Aslan, S., Ekim, T., Vural, M. \& Babaç, M.T. (Eds.). Türkiye Bitkileri Listesi (Damarl Bitkiler). Nezahat Gökyiğit Botanik Bahçesi \& Flora Araştırmaları Derneği Yayını, İstanbul, pp. 627-629.

Okur, S. (2019). Türkiye Epilobium L. (Onagraceae) Taksonlarının Biyosistematik Yönden İncelenmesi (Doktora Tezi). Recep Tayyip Erdoğan Üniversitesi, Fen Bilimleri Enstitüsü, Rize.

Pignatti, S. (1982). Flora d'Italia. Vol. 2. Edagricole, Bolongo.

Punt, W., Hoen, P.P., Blackmore, S., Nilsson, S. \& Le Thomas, A. (2007). Glossary of pollen and spore terminology. Review of Palaeobotany and Palynology 143(1-2): 1-81. 
Rahimi, S., Mehrabian, A.R., Sheidai, M. \& Sadr, M.M. (2018). Pollen Morphology of Onagraceae in Iran. Iranian Journal of Botany 24(1): 16-27. DOI: 10.22092/ijb.2018.122090.1204.

Raimann, R. (1893). [Onagraceae L.] In: Engler, A. \& Prantl, K. (Eds.). Die Natürlichen Pflanzenfamilien. Engelmann, Leipzig.

Raven, P.H. (1968). [Epilobium L.] In: Tutin, T.G., Heywood, V.H., Burges, N.A., Moore, D.M., Valentine, D.H., Walters, S.M. \& Webb, D.A. (Eds.). Flora Europaea. Vol. 2. Cambridge University Press, Cambridge, pp. 308-311.

Raven, P.H. (1976). Generic and sectional delimitation in Onagraceae, tribe Epilobieae. Annals Missouri Botanical Garden 63(2): 326-340.

Raven, P.H. (1980). Hybridization and the nature of species in higher plants. The Canadian Botanical Association Bulletin (supplement) 13: 3-10.

Raven, P.H. (1988). [Onagraceae as a model of plant evolution] In: Gottlieb, L.D. \& Jain, S.K. (Eds.). Plant Evolutionary Biology. Chapman and Hall, New York, pp. 85-107.

Rechinger, K.H. (1964). Flora of Lowland Iraq. J. Cramer, Weinheim.

Sennikov, A. (2011). Chamerion or Chamaenerion (Onagraceae)? The old story in new words. Taxon 60(5): 1485-1488. DOI: https://doi.org/10.1002/tax.605028.

Shteinberg, E.I. (1949). [Onagraceae] In: Shishkin, B.K. (Ed.) Flora of the USSR. Vol. 15. Izdatelstro Akademii Nauk SSSR, Moskva \& Leningrad, pp. 429-465.

Skvarla, J.J., Rowley, J.R., Hoch, P.C. \& Chissoe, W.F. (2008). Unique tetrads of Epilobium luteum (Onagraceae: Onagreae) pollen from Alaska. Brittonia 60(4): 398-404. DOI: 10.1007/ s12228008-9044-х.

Wagner, W.L., Hoch, P.C. \& Raven, P.H. (2007). Revised Classification of the Onagraceae. Systematic Botany Monographs 83: 1-193. 